\title{
SALaMA study protocol: a mixed methods study to explore mental health and psychosocial support for conflict-affected youth in Detroit, Michigan
}

\author{
Lindsay Stark ${ }^{1 *}$ (D), Mackenzie V. Robinson ${ }^{1}$, llana Seff ${ }^{2}$, Wafa Hassan $^{3}$ and Carine Allaf ${ }^{4}$
}

\begin{abstract}
Background: Families resettling to the U.S. from conflict-affected countries in the Middle East and North Africa (MENA) face countless challenges. These families must cope with experiences of armed conflict and forced migration while also assimilating to a new society. According to the 'immigrant paradox,' time spent in a new country can compound the effects of migration and assimilation challenges and lead to deteriorated mental health. This study aims to assess the psychosocial wellbeing of MENA-born or first-generation adolescents attending school in the Detroit metropolitan area (DMA) to understand how schools, families, and communities play a role in supporting these adolescents' wellbeing.
\end{abstract}

Methods: The quantitative component of this mixed methods study will involve a self-administered survey with a sample of students whose responses will be linked to academic records and behavioral assessments. The survey will utilize validated instruments to measure depressive and anxiety symptoms (Hopkins Symptom Checklist-37A), hope (Children's Hope Scale), resilience (Child and Youth Resilience Measure-12), externalizing and prosocial behavior (Hopkins Symptom Checklist-37A, Strengths and Difficulties Questionnaire), school belonging (Psychological Sense of School Membership), and peer relationships (Multidimensional Scale of Perceived Social Support). Differences in outcomes will be analyzed across two strata: students born in the MENA region and first-generation students whose parents immigrated to the US from the MENA region. The qualitative component will involve semistructured key informant interviews with parents, school administrators, educators, and mental health providers, and focus group discussions (FGDs) with a purposive sample of adolescents born - or whose parents were born - in the MENA region. The FGDs will include a participatory ranking activity where participants will be asked to free-list and rank ideas about how schools can better support students like them. Thematic content analysis will be conducted to identify common themes.

Discussion: This study will contribute evidence about the wellbeing of adolescents who come from - or whose parents come from - conflict-affected countries currently living in the U.S. Findings can be used to inform program and policy development to enable schools and their community partners to serve this population more effectively.

Keywords: Mental health, Psychosocial support, Youth, Acculturation, Education, Refugees, Immigrants, Middle East, MENA, Immigrant paradox

\footnotetext{
* Correspondence: lindsaystark@wustl.edu

'Brown School, Washington University in St. Louis, Campus Box 1196, One

Brookings Drive, St. Louis, MO 63130, USA

Full list of author information is available at the end of the article
}

(c) The Author(s). 2020 Open Access This article is distributed under the terms of the Creative Commons Attribution 4.0 International License (http://creativecommons.org/licenses/by/4.0/), which permits unrestricted use, distribution, and reproduction in any medium, provided you give appropriate credit to the original author(s) and the source, provide a link to the Creative Commons license, and indicate if changes were made. The Creative Commons Public Domain Dedication waiver (http://creativecommons.org/publicdomain/zero/1.0/) applies to the data made available in this article, unless otherwise stated. 


\section{Background}

Adolescence is a critical phase of human development, during which physical, neural, and psychological growth are readily influenced by external factors. Experiences during adolescence can have a profound effect on health and wellbeing that last through adulthood [1]. While this developmental period can be challenging for any individual, adolescents who have been - or whose parents have been - resettled from the Middle East and North Africa (MENA) region face a number of unique challenges that may increase their risk of adverse mental and psychosocial health outcomes. Following escape from political conflict and violence at home, forced migrants often endure a multitude of hardships throughout their flight, from a lack of basic resources, to detention, humiliation, and physical and sexual abuse [2]. Those who resettle in the United States may not only struggle to process their loss of home and experiences of migration, but must also adapt to a new language and culture, and learn to navigate complicated legal and public service systems [3]. Further, adolescents coming from conflict-affected settings often spend months or years out-of-school prior to resettlement and may struggle to catch up with their peers academically, all the while at risk of facing routine discrimination, micro-aggressions, and bullying in their new communities $[4,5]$.

Arab immigrant, refugee, and U.S.-born Arab-American adults report higher levels of poor mental health outcomes than non-Arab Americans, including depression and anxiety $[6,7]$. However, despite the emerging literature on adults from Arab-majority countries, fewer studies have focused on adolescents within this same population. The few studies that have been undertaken have shown that children and adolescents resettling in high-income countries, such as the U.S., tend to be at elevated risk of poor psychological outcomes, such as mood and anxiety disorders, compared to those living in the country of origin [3, 8]. Given the known adversities stemming from conflict, migration and acculturation stressors, these findings may not come as a surprise.

What is perhaps more surprising is that time spent in a resettlement country has been shown to exacerbate these mental health risks, both among immigrant adults and adolescents [9]. Within this 'immigrant paradox,' prolonged time lived in the U.S. can result in deteriorated mental health and wellbeing among immigrant children and adolescents compared to first generation U.S.-born children of immigrants $[6,10,11]$. While this finding may seem counterintuitive given the considerable acculturative stress experienced by this population, it has been hypothesized that those newer to the country may fare better relative to those who have resided for longer periods of time due to protective factors unique to immigrant populations, including living in ethnic enclaves upon first arrival to the U.S. Known as the 'ethnic density effect,' this phenomenon has been theorized to contribute to better physical and mental health outcomes among immigrants living in high income countries compared to those living in other areas [12-17].

The available evidence points to several related protective factors for adolescents from conflict-affected countries who have resettled in high-income countries. Perceived community acceptance and support is a critical factor influencing psychosocial health outcomes among this population, together with parental support, family connectedness, and continued links with the cultural and religious practices of the origin country, among others $[18,19]$. The erosion of such protective factors coinciding with increases in 'acculturative stress' can lead to a decline in overall mental health of immigrant adolescents over time [10,11].

Schools in particular are thought to play a central protective role for youth from these settings. For example, studies in the U.S. have found that refugees and asylumseekers reporting a strong sense of school belonging (or high school social capital) tended to have lower levels of psychosocial distress [20-22]. In addition to educating students who have been resettled, and connecting them to a broader community of peers, schools can also provide an environment in which families may build new support networks and relationships. For example, the Colorado Department of Human Services recently found that school support contributed not only to students' integration, but to the integration of parents as well, with parents becoming markedly more involved in their children's schools over time [23]. Practitioners and researchers alike have become increasingly interested in the role of schools in promoting healthy development and improved psychosocial wellbeing among resettled refugees and asylum-seekers, and nascent evidence points to the potential of such school-based interventions in high-income countries.

Within an increasingly hostile political climate, a broader evidence base is urgently needed to develop programs and policies that enable schools and their partners to serve this population effectively. Ongoing conflict in countries such as Syria, Iraq, Libya, and Yemen, contribute to the large number of refugees and asylum-seekers in the U.S. Syria and Iraq, for example, were two of the top five origin countries of refugees and asylum-seekers resettled in the U.S. in 2016 and 2017, together representing over a quarter of new arrivals in each of those years [24]. Additionally, given the recent influx of Arabic newcomers nationally, it is important to explore the nuanced differences in experiences and psychosocial adjustment among adolescent students, with the understanding that needs may differ depending on where and how long they have resided in the US. To bridge these 
gaps in evidence and practice, the SALaMA study aims to assess the mental health and psychosocial wellbeing of adolescent students from conflict-affected, Arabmajority countries living in the largest Arab ethnic enclave in the U.S., with special attention paid to whether they were born in the U.S or abroad.

\section{Methods/design}

\section{Study setting}

This mixed methods, cross-sectional study will take place across three public charter high schools located in the Detroit Metropolitan Area (DMA) of Michigan, which has an extensive history of economic and migratory fluctuations $[25,26]$. Around $15.6 \%$ of the DMA's 4.3 million people live below the federal poverty level with an average life expectancy that is 5 years shorter than comparable populations in other major US cities, including New York City, San Francisco, and Dallas [27, 28].

This setting was chosen for the present study due to its relatively high percentage of Arab immigrant, refugee, and asylum-seeking students. The DMA has the second largest number of Arabs and Arab-Americans in the U.S., coming second only to Los Angeles [29]. Historically, this area has been a popular destination for MENA immigrants and forced migrants/refugees, with $46 \%$ of Dearborn's population identifying as Arab [30, 31]. Cohorts of immigrants and forced migrants/refugees from the MENA region have continually arrived in the U.S. through what are now referred to as the "three waves of Middle East migration," though the exact time periods that define each wave can vary $[30,32]$. The first wave arrived in the latter half of the nineteenth century, and was comprised of individuals who largely sighted seeking opportunities for educational and financial success as the primary reason for their migration [33]. The second wave arrived post-World War II when the U.S. received a large influx of MENA immigrant and refugee families fleeing conflict and poverty, primarily from Lebanon, Iraq, and Yemen [17, 30, 33]. The majority of these families settled in the DMA mostly due to the abundance of jobs available through the Ford Motor company. This second wave is generally credited as fostering the community's social cohesion and Arab-American identity [33-36]. The third wave comprises those who emigrated primarily from Syria, Palestine, Jordan, Egypt, and the Arabian Peninsula after the U.S. Immigration Act was enacted in 1965 [17, 30]. This wave is considered to have had the largest number of MENA migrants, especially with the onset of the Lebanese Civil War in 1975, the Gulf War of 1991, and subsequent invasions of Iraq and Syria post-September 11th [17, 32]. Migrants in this wave tended to join their families who had migrated in previous waves, leading to a sevenfold increase in the number of MENA migrants to the U.S. [17]. Most of these migrants settled in the DMA, creating one of the largest current Arab ethnic enclaves outside of the MENA region [17, 30, 34, 36].

\section{Study design, sample and recruitment}

The three participating schools in our study have an estimated combined enrollment of 2000 students, with the majority of students teachers and staff identifying as Arab.

The primary research questions (RQs) are:

RQ 1: What are the current levels and experiences of mental and psychosocial wellbeing among students who have migrated from abroad, including those of Arab origin, and how do they compare to first generation Arab-American students in the selected schools?

RQ 2: What elements in the family, school, community, and district contribute to the mental and psychosocial wellbeing of these students in the selected schools? RQ 3: What kinds of additional support do adolescents and adults identify to improve the mental and psychosocial wellbeing of these students in the selected schools?

This study will utilize a mixed methods design. The quantitative portion of the study will involve a selfadministered survey with students enrolled in Arabic language classes aged 13+ years from participating schools. The qualitative portion of the study will involve (1) semi-structured key informant interviews with parents, school administrators, educators, and mental health providers and (2) focus group discussions (FGDs) with a purposive sample of adolescents who were born - or whose parents were born - in the MENA region. The FGDs will include a participatory ranking activity in which participants will be asked to free-list and rank ideas about how high schools can better support resettled students from conflict-affected countries. The research protocol has been approved by the Institutional Review Board (IRB) at Washington University in St. Louis (IRB201905151) and the participating schools' principals.

\section{Quantitative data collection}

A structured survey will be self-administered by respondents using school computers. Data will be collected on students' socio-demographics, public services usage, experiences prior to and following resettlement (if applicable), and psychosocial wellbeing. Due to the unique ethnic/racial composition of students at these high schools, researchers will utilize census sampling to ensure adequate sample sizes for each stratum (further described below). The research team will visit every Arabic class at each school to explain the study and distribute 
parental consent forms. Aside from students aged 18+ years, only students whose parents sign and return consent forms will be approached for assent on the day of data collection. Student assent will be obtained prior to the survey and students will be informed of their rights as participants. The survey was developed in English and translated into Arabic; both versions will be available to all students who participate. The research team will also work with the school offices to access records of student performance, such as academic grades and behavioral assessments. Several steps will be taken to protect participant privacy throughout data collection and analysis. The survey will be self-administered using a passwordprotected school computer. Completed surveys will automatically upload to a secure server that is accessible only by research staff and the local files will be erased from the device. Data files will be de-identified and indexed by a participant code assigned as part of the study to reduce the possibility that confidential information will be leaked beyond the intended research staff in the event that study instruments are lost or stolen. All data will be disposed of 7 years after completion of the study and all electronic records will be permanently deleted. All data will be disposed of 7 years after completion of the study and all electronic records will be permanently deleted.

The survey will examine the following key outcomes using scales/instruments previously validated to measure various dimensions of mental health and psychosocial wellbeing with refugee and asylum-seeking populations in high-income countries: depressive and anxiety symptoms, hope, resilience, externalizing and prosocial behavior, school belonging, and peer relationships (See Table 1).

\section{Qualitative data collection \\ Focus group discussions}

The researchers will conduct FGDs with students to understand the risk and resilience factors associated with post-migration experiences of students from conflictaffected, Arab-majority countries. With assistance from school staff, purposive sampling will be used to prioritize the inclusion of students. Inclusion criteria include 1) being 13 years of age or older, 2) being born in -- or having a parent born in - a MENA country 3 ) active school enrollment status, and 4) fluency in English or Arabic. It is anticipated that up to 12 FGDs, stratified by gender, will be required to reach saturation. FGDs will be conducted using a semi-structured guide consisting of several open-ended questions, including a series of probing questions, to develop an understanding of the students' social environment at school. Questions include:

- What are some of the challenges of making new friends at your school?
- How do you get along with other students that do not speak Arabic or come from Arab countries?

- Who are some of the adults in the school that you would go to if you had a personal problem, like a problem at home or with another student?

The FGD will then lead into the Participative Ranking Methodology [46], a qualitative research method in which student participants will be asked to discuss and prioritize ways in which high schools can support students resettled from conflict-affected countries.

\section{Parent/caregiver interviews}

Up to 30 in-person parent interviews will be conducted across the three schools until saturation is reached. Inclusion criteria for the purposive selection of parents includes 1) having a child who is first-generation or who was born in a MENA country and 2) fluency in English or Arabic. A semi-structured interview guide will be used to explore parental relationships with their children, as well as pre- and post-migration experiences for families. The interview guide is designed to gain insight into the challenges and opportunities for strengthening students' supportive environments. Sample questions include:

- How do you feel about your new community?

- What are some of the conversations you have had in your family about mental health?

- What are some challenges you've had as a family since being here?

\section{Key informant interviews}

Approximately 10-20 KIIs will be completed with representation from a diverse range of stakeholders who work with resettled families from Arab-majority countries. Separate semi-structured interview guides were developed for use with educators, service providers, administrators, and government officials, respectively. Similar to the parent/ caregiver interviews, these guides are meant to gain insight into the challenges and opportunities for strengthening students' supportive schools and communities.

FGDs and interviews with parents/caregivers and school staff will take place in a private room provided by schools. Key informant interviews will take place at a location of the participant's choice. Informed consent will be obtained from all FGD and interview participants and consent forms will be available in both English and Arabic. All FGDS and interviews will be recorded (contingent on participant consent) and transcribed. Arabic interpreters will be available for any participants who require such assistance. Researchers will take extensive field notes during qualitative data collection. Handwritten notes will be typed into a digital format and de- 


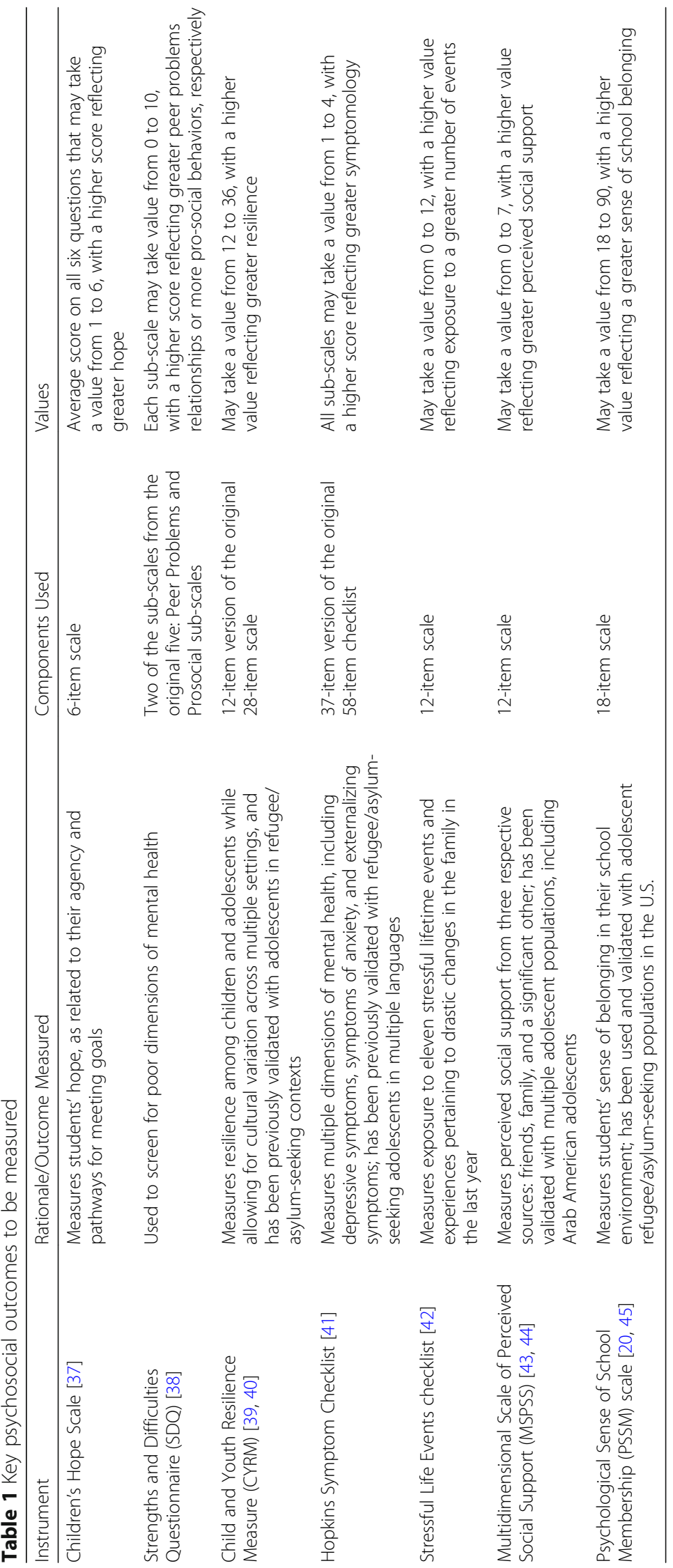


identified immediately after an interview or group discussion. The handwritten notes will then be destroyed. Typed notes and audio recordings will be stored on a password-protected computer, with only research staff allowed access to the data. Any transcripts produced from audio files of qualitative data collection sessions will be de-identified and stored in the same manner as the audio files and field notes. All data will be disposed of 7 years after completion of the study. All paper records will be shredded prior to disposal and audio files will be deleted.

\section{Quantitative sample size calculations and analysis}

The survey sample will consist of two study strata including (1) students who were born outside of the US, and (2) students who were born in the US but whose parents immigrated to the US. The necessary sample size for the quantitative sample has been calculated to detect a difference in the proportion of students with depression, at $d=0.40$, between the two study strata. Calculations were conducted assuming $\alpha<0.05,80 \%$ power, and a one-to-one ratio of students in both sample groups. As a result, a total of 196 students (98 in each stratum) are required.

Differences in the outcomes of interest between the two strata will be tested using a first-order linear regression; tests will be deemed significant at $p<0.05$. Multivariate linear regressions will then be employed to assess whether bivariate relationships between group membership and the outcomes of interest hold when controlling for other covariates, including various sociodemographic characteristics, measures of academic performance, and stressful life events. Lastly, effect modification will be assessed by examining whether any covariates deemed to be associated with the outcomes of interest in the previous step have a differential impact on the outcomes across the two strata. The significance of potential effect modifiers will be identified through the use of interacted linear regressions, where group membership is interacted with key covariates. Additional analyses will explore similar relationships between group membership and secondary outcomes around academic performance. All quantitative analyses will be conducted using Stata14 [47].

\section{Qualitative assessment and analytic plan}

Qualitative data will be analyzed using a combination of inductive and deductive thematic analysis, allowing themes to emerge from the data inductively while using themes from previous studies with similar population $[48,49]$. Additionally, because data will be analyzed from each stratum separately, constant comparative method will be used to compare and contrast themes across strata [50].

\section{Discussion}

The SALaMA study is the first study to explore the mental health and wellbeing of adolescents who come from - or who have parents who came from - the MENA region and settled in the US. While the challenges associated with migrating to a new country may influence the degree to which newcomer students are able to adapt to their new country, it is also important to understand how this adaptation process might differ for students whose families resettle within more insulated Arab enclaves. The unique ethno-cultural makeup of this study's setting will allow the findings to speak to the ethnic density effect and its correlation with mental health and psychosocial wellbeing among MENA adolescents residing in an ethnic enclave. The findings can also help to explore if and how the immigrant paradox pertains to this unique population, building on previous studies [51, 52]. All findings will be shared directly with participating schools and organizations as well as through publication in peer-reviewed journals.

There remains a dearth of evidence-based solutions for developing more inclusive policy and program development for refugees and forced migrants. We hope our findings will be used to inform interventions at the district, state, and national levels in high income countries to enable schools and their community partners to serve this population more effectively.

\section{Abbreviations}

DMA: Detroit Metropolitan Area; FGDs: Focus Group Discussions; MENA: Middle East and North Africa region

\section{Acknowledgements}

The authors are grateful for the support from the school principals of all participating schools, Global Educational Excellence schools, and Qatar

Foundation International (QFI).

\section{Authors' contributions}

LS conceptualized and designed the study, made critical revisions to the manuscript, and gave final approval of the version to be published. MR and IS drafted the manuscript. WH and CA provided final approval of the version to be published. All authors read and approved the final manuscript.

\section{Funding}

This study is made possible through support and funding from the Qatar Foundation International (QFI). The funding body provided peer-review of the proposed research, connected the research team with on the ground partners in Michigan schools, and reviewed and approved the final manuscript. The funding sponsor can be contacted at callaf@qfi.org.

Availability of data and materials

The de-identified datasets generated and/or analysed during the current study may be available from the corresponding author on reasonable request.

Ethics approval and consent to participate

Study protocol was approved by the Institutional Review Board of

Washington University in St. Louis (IRBID 201905151). Consent and assent to participate will be written.

Consent for publication Not applicable. 


\section{Competing interests}

The authors declare that they have no competing interests.

\section{Author details}

'Brown School, Washington University in St. Louis, Campus Box 1196, One Brookings Drive, St. Louis, MO 63130, USA. ${ }^{2}$ Mailman School of Public Health, Columbia University, 722 West 168th St., New York, NY 10032, USA. ${ }^{3}$ Global Educational Excellence, 2455 S. Industrial Hwy, Ann Arbor, MI 48104, USA. ${ }^{4}$ Qatar Foundation International, 1225 New York Avenue NW, Suite 500, Washington, DC 20005, USA

\section{Received: 20 December 2019 Accepted: 2 January 2020}

\section{Published online: 10 January 2020}

\section{References}

1. Patton GC, Sawyer SM, Santelli JS, Ross DA, Afifi R, Allen NB, et al. Our future: a lancet commission on adolescent health and wellbeing. Lancet Lond Engl. 2016;387(10036):2423-78.

2. Abubakar I, Aldridge RW, Devakumar D, Orcutt M, Burns R, Barreto ML, et al. The UCL-Lancet Commission on migration and health: the health of a world on the move. Lancet. 2018;392(10164):2606-54.

3. Fazel M, Reed RV, Panter-Brick C, Stein A. Mental health of displaced and refugee children resettled in high-income countries: risk and protective factors. Lancet Lond Engl. 2012;379(9812):266-82.

4. Stepping Up: Refugee Education in Crisis [Internet]. UNHCR; 2019; p. 56. Available from: https:/unhcrsharedmedia.s3.amazonaws.com/2019/ Education-report_30-August_2019/Education+Report+2019-Final-web.pdf.

5. Hadfield K, Ostrowski A, Ungar M. What can we expect of the mental health and well-being of Syrian refugee children and adolescents in Canada? Can Psychol Can. 2017;58(2):194-201.

6. Pampati S, Alattar Z, Cordoba E, Tariq M, de Leon CM. Mental health outcomes among Arab refugees, immigrants, and U.S. born Arab Americans in Southeast Michigan: a cross-sectional study. BMC Psychiatry. 2018;18(1):379.

7. Dallo FJ, Kindratt TB, Snell T. Serious psychological distress among nonHispanic whites in the United States: the importance of nativity status and region of birth. Soc Psychiatry Psychiatr Epidemiol. 2013;48(12):1923-30.

8. Bronstein I, Montgomery P. Psychological distress in refugee children: a systematic review. Clin Child Fam Psychol Rev. 2011;14(1):44-56.

9. Abdulrahim S, Baker W. Differences in self-rated health by immigrant status and language preference among Arab Americans in the Detroit Metropolitan Area. Soc Sci Med. 2009;68(12):2097-103.

10. Palacios N, Guttmannova K, Chase-Lansdale PL. Early reading achievement of children in immigrant families: is there an immigrant paradox? Dev Psychol. 2008:44(5):1381-95.

11. Perreira KM, Harris KM, Lee D. Making it in America: high school completion by immigrant and native youth. Demography. 2006;43(3):511-36.

12. Eschbach K, Ostir GV, Patel KV, Markides KS, Goodwin JS. Neighborhood context and mortality among older Mexican Americans: is there a barrio advantage? Am J Public Health. 2004;94(10):1807-12.

13. Nobles CJ, Valentine SE, Zepeda ED, Wang Y, Ahles EM, Shtasel DL, et al. Residential segregation and mental health among Latinos in a nationally representative survey. J Epidemiol Community Health. 2017;71(4):318-23.

14. Das-Munshi J, Becares L, Dewey ME, Stansfeld SA, Prince MJ. Understanding the effect of ethnic density on mental health: multi-level investigation of survey data from England. BMJ. 2010;341. https://doi.org/10.1136/bmj.c5367.

15. Pickett K, Wilkinson R. People like us: ethnic group density effects on health. Ethn Health. 2008;13(4):321-34

16. Lester H. Ethnic density and mental health. BMJ. 2010;341. https://doi.org/ 10.1136/bmj.c5367.

17. Foad HS. Waves of Immigration from the Middle East to the United States [Internet]. Rochester: Social Science Research Network; 2013. Report No.: ID 2383505. https://doi.org/10.2139/ssrn.2383505.

18. Ahmed SR, Kia-Keating M, Tsai KH. A structural model of racial discrimination, acculturative stress, and cultural resources among Arab American adolescents. Am J Community Psychol. 2011;48(3-4):181-92.

19. Fazel $M$, Betancourt TS. Preventive mental health interventions for refugee children and adolescents in high-income settings. Lancet Child Adolesc Health. 2018;2(2):121-32.

20. Kia-Keating $\mathrm{M}$, Ellis $\mathrm{BH}$. Belonging and connection to school in resettlement: young refugees, school belonging, and psychosocial adjustment. Clin Child Psychol Psychiatry. 2007;12(1):29-43.
21. Montgomery E. Trauma, exile and mental health in young refugees: mental health in young refugees. Acta Psychiatr Scand. 2011;124:1-46.

22. Trentacosta CJ, McLear CM, Ziadni MS, Lumley MA, Arfken CL. Potentially traumatic events and mental health problems among children of Iraqi refugees: the roles of relationships with parents and feelings about school. Am J Orthop. 2016;86(4):384-92.

23. Lichtenstein G, Puma J, Engelman A, Miller M. The Refugee Integration Survey and Evaluation (RISE) Year Five: Final Report A study of refugee integration in Colorado [Internet]; 2016. p. 76. https://www. immigrationresearch.org/system/files/rise-year-5-report.pdf

24. Batalova JBBB and J. Refugees and Asylees in the United States [Internet]. migrationpolicy.org. 2019. https://www.migrationpolicy.org/article/refugeesand-asylees-united-states.

25. Inhorn MC. America's Arab refugees: vulnerability and health on the margins [internet]. Stanford: Stanford University Press; 2018.

26. Schopmeyer K. A Changing Demographic Portrait. In: Arab Detroit 9/11: Life in the Terror Decade [Internet]. Detroit: Wayne State University Press; 2011. (Great Lakes Books)

27. Chetty R, Stepner M, Abraham S, Lin S, Scuderi B, Turner N, et al. The association between income and life expectancy in the United States, 2001-2014. JAMA. 2016;315(16):1750-66.

28. Bureau USC. Poverty Status in the 12 months - 2013-2017 American community survey 5-year estimates: Detroit-Warren-Dearborn, MI Metro Area [Internet]. Am Fact Finder. 2019; https://factfinder.census.gov/faces/ tableservices/jsf/pages/productview.xhtml?pid=ACS_17_5YR_S1701 \&prodType=table

29. Demographics [Internet]. Arab American Institute Foundation. 2018. https://assets.nationbuilder.com/aai/pages/9843/attachments/ original/1551198642/National_Demographics_SubAncestries_2018. pdf?1551198642.

30. Shryock A, Abraham N. Arab Detroit : from margin to mainstream. Detroit: Wayne State University Press; 2000.

31. Bureau USC. People Report Ancestry - 2017 American Community Survey 1-Year Estimates: Detroit-Warren-Dearborn, MI Metro Area [Internet]. https://factfinder.census.gov/faces/nav/jsf/pages/index.xhtml.

32. Arab American National Museum. Arab American immigration | reclaiming identity: dismantling Arab stereotypes [internet]. Reclaiming Identity: Dismantling Arab Stereotypes. 2011. http://arabstereotypes.org/who-arearab-americans/arab-american-immigration.

33. Rignall K. Building the infrastructure of Arab American identity in Detroit. In: Arab Detroit : from margin to mainstream. Detroit: Wayne State University Press; 2000.

34. Shalabi $\mathrm{L}$. The relationship between cultural identity and academic achievement of Arab American students in reading, mathematics, and language in a suburban middle and high school. Detroit: Wayne State University; 2001.

35. Kiskowski WL. Arab American identities and the cultural landscape of Dearborn, Michigan; 2017.

36. Camarota SA. Immigrants from the Middle East: 2002. https://cis.org/sites/ cis.org/files/articles/2002/back902.pdf

37. Snyder CR, Hoza B, Pelham WE, Rapoff M, Ware L, Danovsky M, et al. The development and validation of the Children's Hope scale. J Pediatr Psychol. 1997;22(3):399-421.

38. Goodman R, Ford T, Simmons H, Gatward R, Meltzer $H$. Using the strengths and difficulties questionnaire (SDQ) to screen for child psychiatric disorders in a community sample. Br J Psychiatry. 2000;177(6):534-9.

39. Liebenberg L, Ungar M, LeBlanc JC. The CYRM-12: a brief measure of resilience. Can J Public Health Rev Can Sante Publique. 2013;104(2):e131-5.

40. Panter-Brick C, Hadfield K, Dajani R, Eggerman M, Ager A, Ungar M. Resilience in context: a brief and culturally grounded measure for Syrian refugee and Jordanian host-community adolescents. Child Dev. 2018;89(5):1803-20.

41. Bean T, Derluyn I, Eurelings-Bontekoe E, Broekaert E, Spinhoven P. Validation of the multiple language versions of the Hopkins symptom Checklist-37 for refugee adolescents. Adolescence. 2007;42(165):51-71.

42. Bean T, Eurelings-Bontekoe E, Derluyn I, Spinhoven P. Hopkins Symptom Checklist-37 for Adolescents (Hscl-37a): User's Manual. Oegstgeest: Stichting Centrum '45: 2004

43. Zimet GD, Dahlem NW, Zimet SG, Farley GK. The multidimensional scale of perceived social support. J Pers Assess. 1988;52(1):30-41.

44. Ramaswamy V, Aroian KJ, Templin T. Adaptation and psychometric evaluation of the multidimensional scale of perceived social support for Arab American adolescents. Am J Community Psychol. 2009;43(1-2):49-56. 
45. Goodenow C. The psychological sense of school membership among adolescents: scale development and educational correlates. Psychol Sch. 1993;30(1):79-90.

46. Stark L, Ager A, Wessells M, Boothby N. Developing culturally relevant indicators of reintegration for girls, formerly associated with armed groups in Sierra Leone using a participative ranking methodology. Interv Int J Ment Health Psychosoc Work Couns Areas Armed Confl. 2009;7(1):4-16.

47. Stata Statistical Software: Release 14. College Station, TX: StataCorp LLC; 2015

48. Boyatzis RE. Transforming qualitative information: Thematic analysis and code development, vol. xvi. Thousand Oaks: Sage Publications, Inc; 1998. p. 184. (Transforming qualitative information: Thematic analysis and code development.)

49. Braun V, Clarke V, Hayfield N, Terry G. Thematic analysis. In: Liamputtong P, editor. Handbook of research methods in health social sciences [internet]. Singapore: Springer Singapore; 2019. p. 843-60. https://doi.org/10.1007/978981-10-5251-4_103.

50. Silverman D. Interpreting qualitative data: a guide to the principles of qualitative research. 4th ed. Los Angeles: Sage; 2011. p. 500.

51. Abuelezam NN, El-Sayed AM, Galea S. Relevance of the "immigrant health paradox" for the health of Arab Americans in California. Am J Public Health. 2019;109(12):1733-8.

52. Kumar R, Seay N, Karabenick SA. Immigrant Arab adolescents in ethnic enclaves: physical and phenomenological contexts of identity negotiation. Cultur Divers Ethnic Minor Psychol. 2015;21(2):201-12.

\section{Publisher's Note}

Springer Nature remains neutral with regard to jurisdictional claims in published maps and institutional affiliations.

Ready to submit your research? Choose BMC and benefit from:

- fast, convenient online submission

- thorough peer review by experienced researchers in your field

- rapid publication on acceptance

- support for research data, including large and complex data types

- gold Open Access which fosters wider collaboration and increased citations

- maximum visibility for your research: over $100 \mathrm{M}$ website views per year

At $\mathrm{BMC}$, research is always in progress.

Learn more biomedcentral.com/submissions 